\title{
METHODOLOGY OF LANDSCAPE MONITORING IN ASMA AT THE ADMIRALTY BAY: APPLICATION IN KELLER PENINSULA
}

http://dx.doi.org/10.4322/apa.2014.054

\author{
Priscila Faria Gomes ${ }^{1, *}$, Cristina Engel de Alvarez ${ }^{1}$ \\ 'Universidade Federal do Espírito Santo, Vitória, ES, Brazil \\ *e-mail: priscila_fariagomes@hotmail.com
}

\begin{abstract}
The first Brazilian buildings on the Antarctic Continent date from 1984, with the establishment of isolated and readymade structures from Brazil, whose primary function was supporting the development of research and marking the Brazilian intention of developing long-term activities in that place. Since then, the Comandante Ferraz Antarctic Base, located in Keller Peninsula, has undergone deep and disorganized transformations, reaching 2,250 $\mathrm{m}^{2}$ in its main body to date, not considering the individual units. At first the establishment of the Base and its scale indicated minimal changes in the natural landscape and would allow the complete recovery of the environment, if there was a need for its removal. However, concurrent with its growth, the need for assessing the impact caused by the human presence in the region from a landscape perspective was verified. Thus, this study has the purpose of obtaining results with the view to creating a methodology of monitoring and subsequent analysis of the landscape impact on Antarctic environment and applying it to Keller Peninsula. The morphological approach is aimed at assuring the ecological sustainability of that landscape, keeping the large structures working and establishing the link between past and present.
\end{abstract}

Keywords: Antarctica, methodology, sectorial measurement, tracking

\section{Introduction}

Admiralty Bay, an Antarctic Specially Managed Area (ASMA), is an area of undoubted value to science and the environment. As the first ASMA of Antarctica region, the occupancy of the Admiralty Bay demands special care, considering also the replicability of monitoring methods proposed to apply them in other areas of the Antarctica region. Accordingly, the issue of the value of the landscape is of paramount importance, particularly given the difficulty establishing procedures of analysis and the valuation criteria. The landscape's monitoring not only allows us to evaluate and monitor human activities in Admiralty Bay, but also helps us to identify changes in its covering vegetation, in the increasing and/ or decreasing of glaciers, and in the new

land use and occupation performed by the animals. Thus, the landscape's monitoring can identify possible animals' behavioural changes that may occur due to new landscape configuration. Thus, a methodology for monitoring of the landscape of the Admiralty Bay was developed in order to subsequently assess the impacts caused by human occupation in the location, with the methodological test to verify the applicability and feasibility performed in Keller Peninsula, where the Comandante Ferraz Brazilian Antarctic Base is located (Gomes, 2009).

The choice of the Keller Peninsula as initial place is justified by the following aspects: 1) the adoption of the Carneiro's concept (2006) where "[...] the landscape is the 


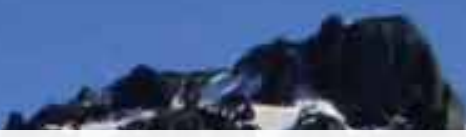

result of a dynamic combination of physical, biological, and human elements, which interconnected one with other, make a single and undivided set [...]"(p. 20), and as the Peninsula is a clearly defined geographic portion, it is understood that the sense of unity is met; 2) because it has conserved and impacted areas, as well as elements related to cultural heritage; 3 ) because it is the place containing most of Brazilian buildings.

\section{Materials and Methods}

Aiming to create repeatable procedures periodically, the methodological proposal is started from the establishment of the so called IRP - Image Reference Points -, placed so as to allow an image scanning of the entire Peninsula, noting that the repetitions have been done always from the same point and directed to the same predetermined angle of vision. Initially, the intervals for repeating the procedures were defined at 2-, 5-, and 10-year, i.e., in 2012, 2015, and 2020.

The establishment of monitoring points started from the three possible strands of work: i) land points - collected $10 \mathrm{~m}$ away from the coastline, with views both inside and outside the Peninsula; ii) sea points - collected from an inflatable boat up to $100 \mathrm{~m}$ away from the coastline, with views for the Peninsula and Admiralty Bay; iii) air points - collected from a helicopter.

The views were defined from the ability to capture pictures using the photographic equipment available (Nikon D-90 camera) covering the entire coast of the Peninsula. The Nikon D-90 camera has an 18-105 mm lens, which allows an aperture of $75^{\circ}$. Based on this data, 8 pictures oriented at each predetermined point can be taken in order to fully cover every georeferenced point, with $360^{\circ}$ images (Figure 1). The taking of pictures at each point follows two lines: the first, directed towards the Peninsula perpendicular to the coast in order to record $360^{\circ}$ pictures of each point. Thus, the georeferenced points were established for obtaining Image Reference Points (IRP) both on sea and land. It should be noted that the Keller Peninsula is the main focus chosen for monitoring, taking into account the views from sea to land and vice versa. For each IRP eight images were used oriented (N, NE, E, SE, S, SW, W, NW, clockwise direction) and, on

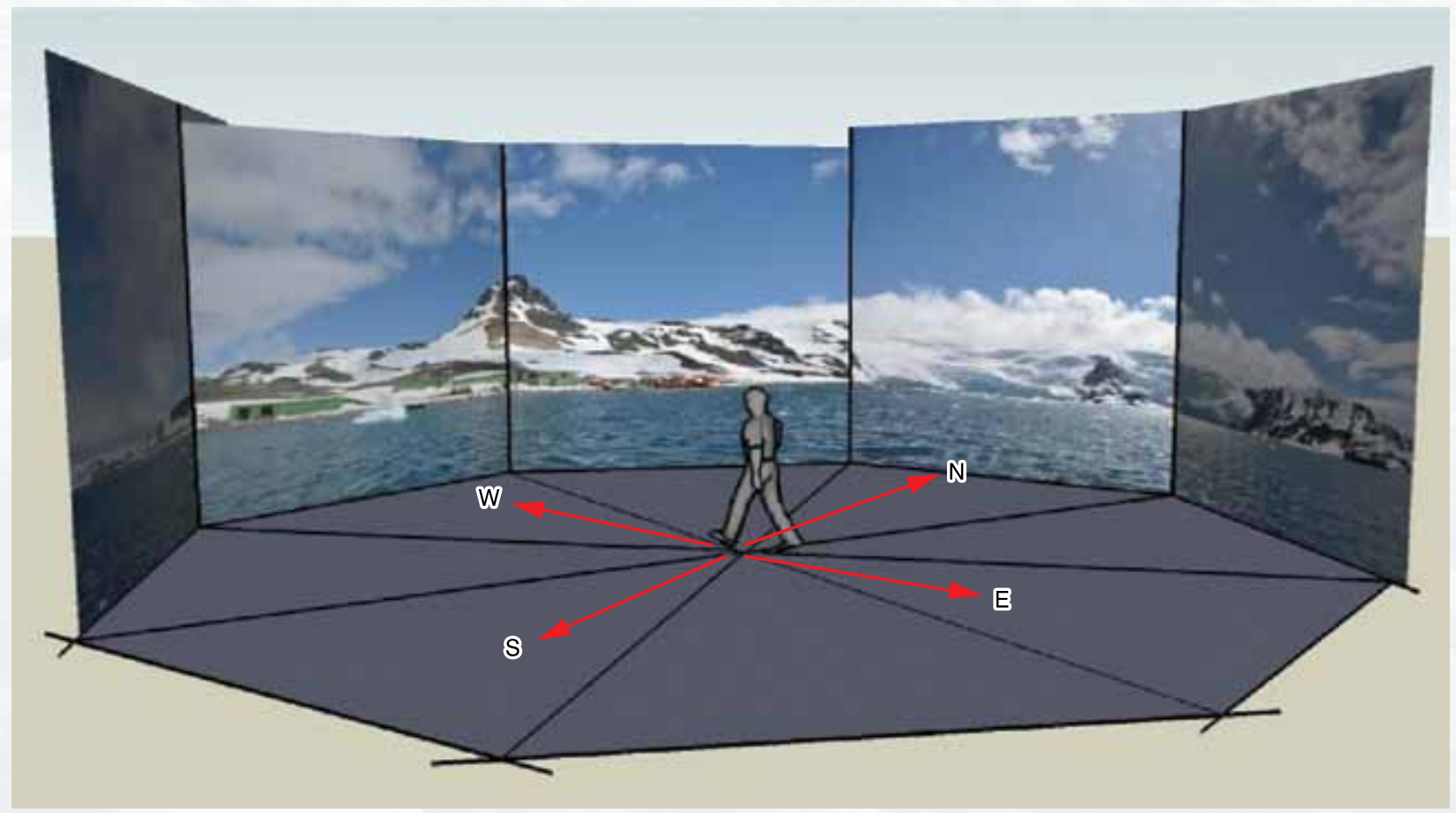

Figure 1. Croquis drawing of obtaining images from IRP 16. 
the sea points, three or more images perpendicular to the land line in order to subsequently design mosaics (Figure 2).

\section{Results}

\section{Determination of the land Image Reference}

Points (IRPs)

The achievement of the land IRPs was done through the use of georeferenced base map. For determining the land points a $10 \mathrm{~m}$ off-set line from the coastline was employed, towards the inside of the Peninsula, in order to bear tidal ranges. From that off-set line, several distances for establishing the points were tested, and it was concluded that to achieve a photographic scan of the entire Keller Peninsula 25 points would be ideal. The off-set line was divided into 25 georeferenced points equidistant from each other about $300 \mathrm{~m}$ straight (Figure 3). From that division were obtained IRPs from A to Y, where each has a specific coordinate.

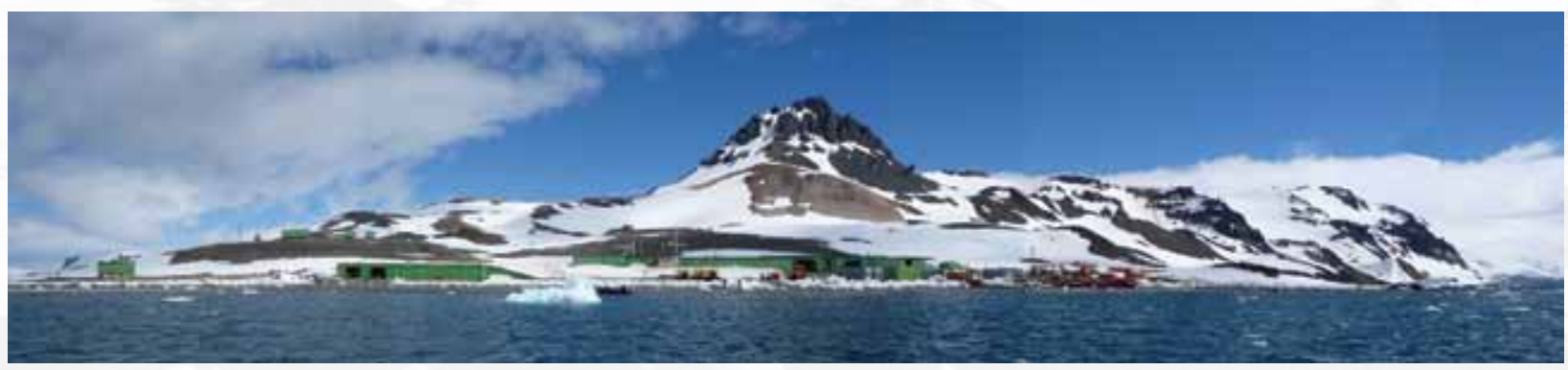

Figure 2. Example of mosaic designed from IRP 16.
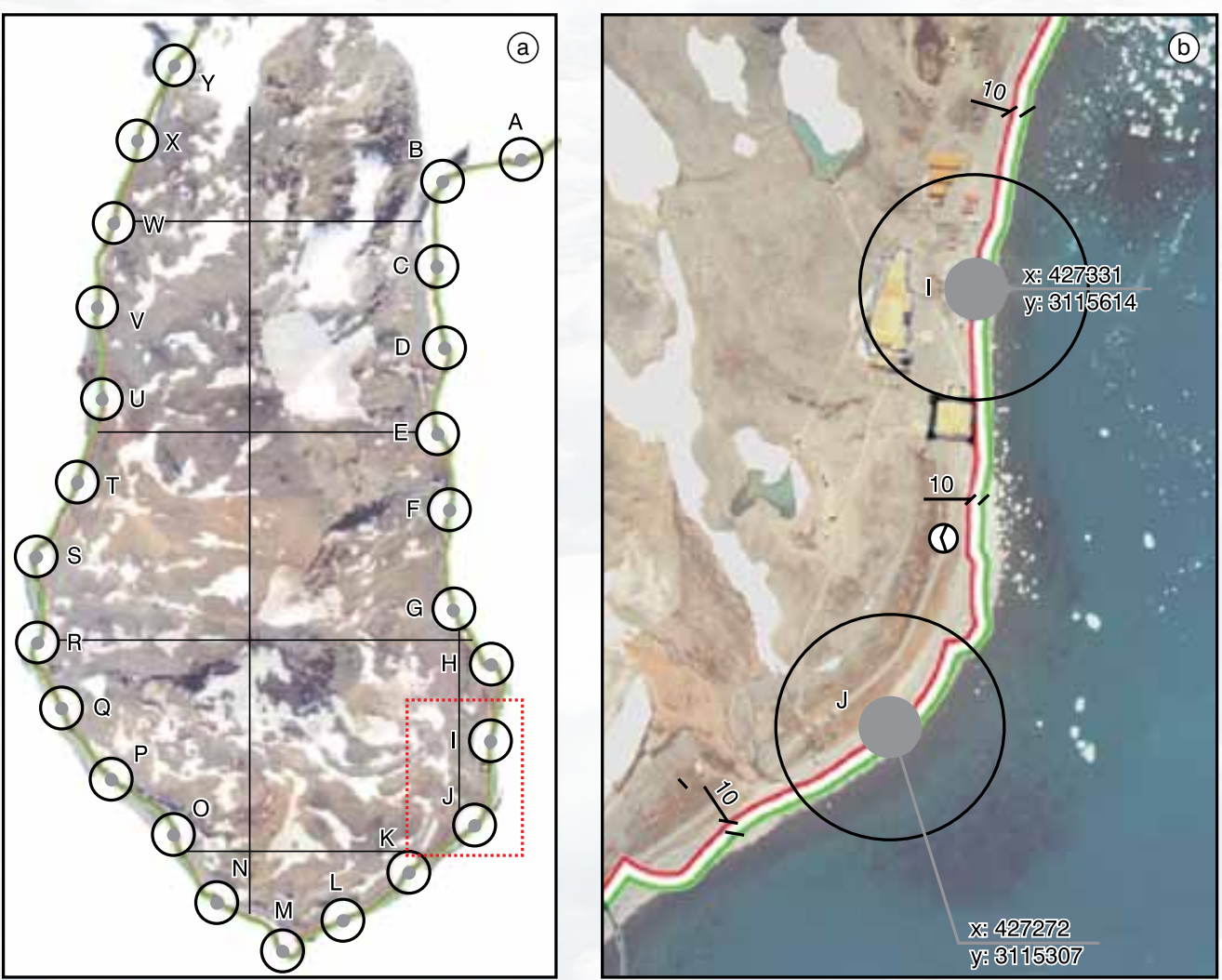

Figure 3. a) Georeferenced IRPs equidistant from each other; b) detail of the referenced IRPs and 10 m off-set line. 

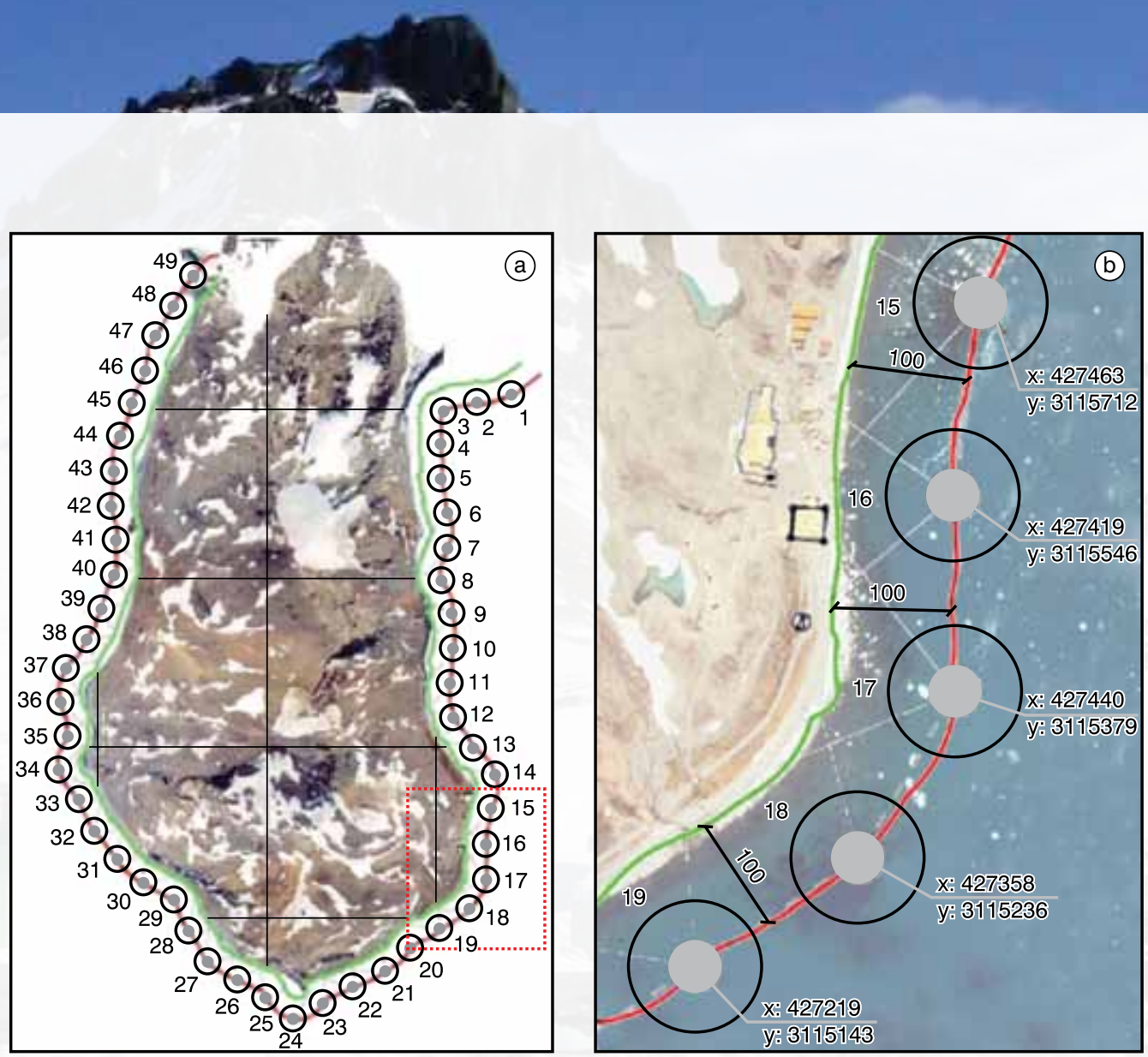

Figure 4. a) Georeferenced IRPs equidistant from each other; b) detail of the georeferenced IRPs and $100 \mathrm{~m}$ off-set line.

Determination of the sea Image Reference Points (IRPs)

The achievement of the sea IRPs was done through the use of the same georeferenced base map as used for the land IRPs. After tests for determination of the sea points an off-set line $100 \mathrm{~m}$ away from the coastline was employed in order to bear every possible view of the Peninsula while not allowing overlap of the images. From that off-set line several distances were tested to determine the points, and it was concluded that to achieve a photographic scan of the entire Keller Peninsula 49 points would be sufficient. Then applied the same way of division as the land points thus resulting in 49 georeferenced points equidistant from each other about $160 \mathrm{~m}$ between them (Figure 4). From that division were obtained IRPs from 1 to 49 , where each has a specific coordinate.

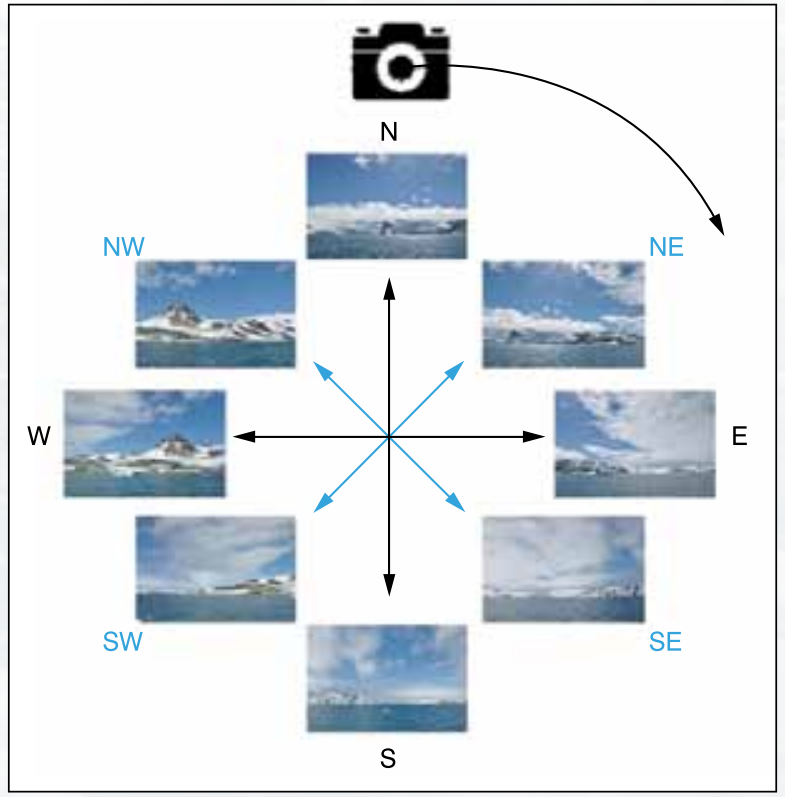

Figure 5. Example of scheme for obtaining pictures (IRP 16)
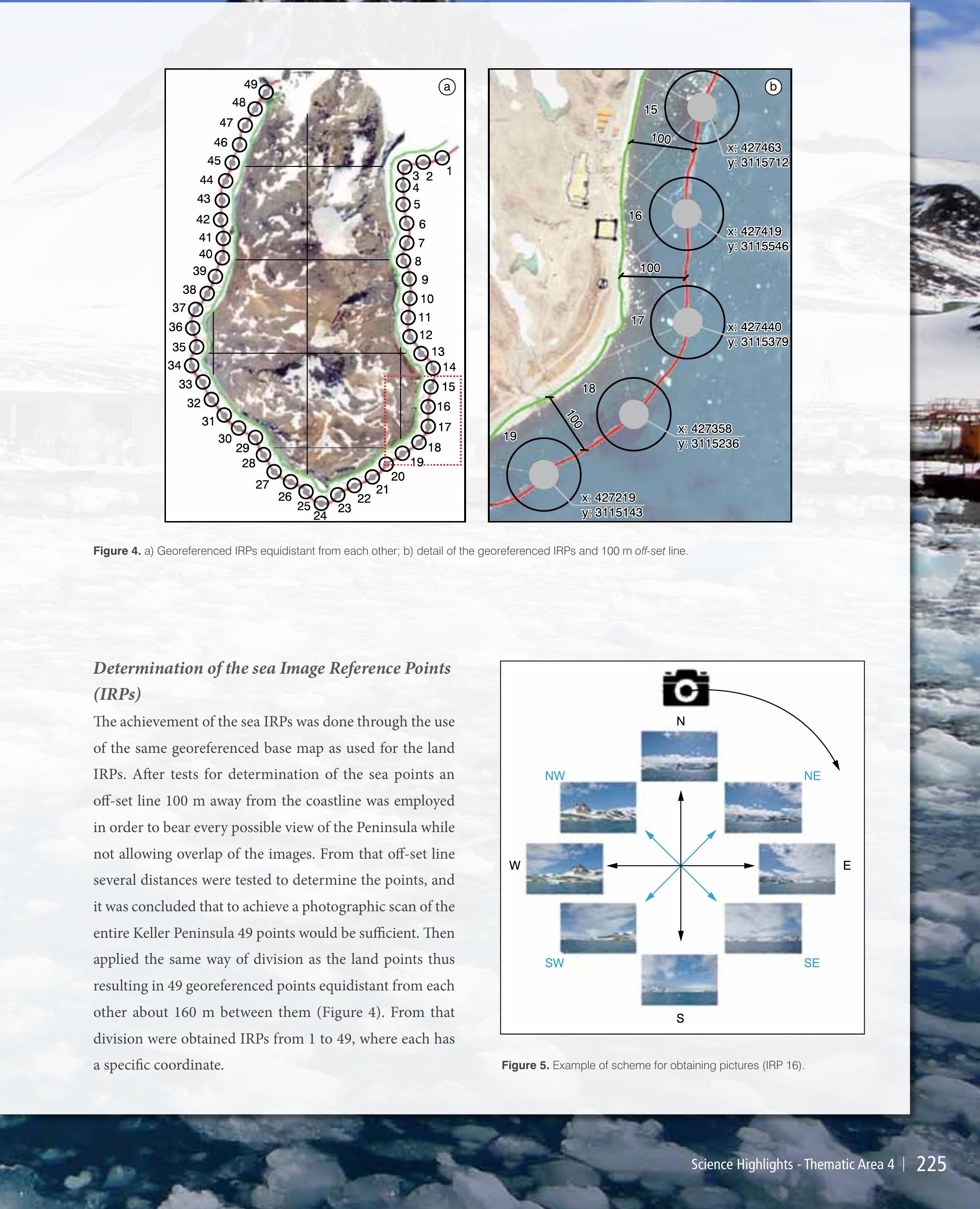


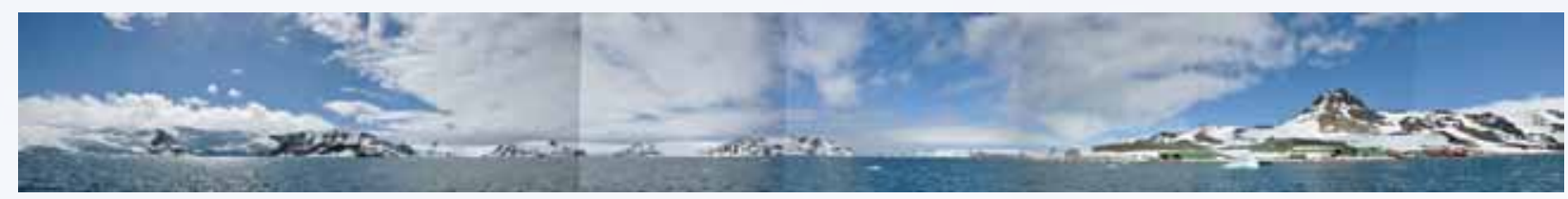

Figure 6. Model of panoramic image arrange from the attainment of pictures of the IRP 16

\section{Attainment of pictures in the field}

In the field, in the summer 2010, in addition to GPS MAP 76 - GARMIN device and the photographic material a compass to the precise orientation of the pictures was used. The inadequacy of the IRPs numbers 1, 2, 3 and 49 to obtain figures due to close proximity to glaciers providing risk for field staff was also observed; therefore those points were removed from the study. To obtain the pictures of the land IRPs the same methodology described previously was employed, with the aid of a compass and GPS. In obtaining pictures at each IRP it was decide to take three pictures for each oriented view in order to assure quality and choice of pictures, highlighting the difficulty to verify the results in situ, due to excessive light or due to constant wind. Thus, at each IRP 24 pictures were taken, starting from North and following in clockwise direction to make the subsequent tabulation easy (Figure 5).

\section{Conclusion}

In the summer 2010 pictures of the land and sea IRPs could be obtained, creating a database with $360^{\circ}$ panoramic images of each IRP (Figure 6) and also the mosaic of the entire Keller Peninsula. That database has allowed for the monitoring of landscape changes of the region and to assess the impact caused by either human action or natural phenomena.

From both that database and the cataloging of those pictures it is aimed to evaluate the situation of the current landscape and to propose guidelines for possible interventions, mainly those related to news buildings. The climatic conditions and particularly the accumulation of snow harmed the work in progress since the need for visualization of the landscape landmarks, such as the "Cousteau's Whale" and the delimitation of trails. It was not possible to perform a panoramic flight over the Keller Peninsula, but the air pictures are needed to add more information to that obtained from land and sea IRPs. Past data could not be analyzed and should not be used as a comparison because of the inexistence of base information or exact location of the place the pictures had been taken, which could lead to an erroneous assessment of the situation of the past. In spite of all the difficulties, the feasibility of the methodology used in this study was also noted, permitting repetition in Admiralty Bay.

\section{Acknowledgements}

We thank the FAPES (Foundation for Support of Science and Technology of the Espírito Santo), the CNPq (National Council for Scientific and Technological Development), and the SECIRM (Secretariat of the Interministerial for Sea Resources).

We also thank National Institute of Science and Technology for Environmental Research in Antarctica (CNPq, process \# 574018/2008-5 and FAPERJ, process \# E-16/170,023/2008).

\section{References}

Carneiro, A. B. (2006). Paisagem: conceitos, personagens, enquadramentos. 112 f. Projeto de Graduação (Graduação) Departamento de Arquitetura e Urbanismo, UFES, Vitória

Gomes, P. F. (2009). Proposta de metodologia para avaliação de impacto paisagístico : aplicação nas instalações brasileiras na Antártica. 115 f. Projeto de Graduação (Graduação) - Departamento de Arquitetura e Urbanismo, UFES, Vitória. 